\title{
Association of Storage and Processing Functions in the Dorsolateral Prefrontal Cortex of the Nonhuman Primate
}

\author{
Richard Levy and Patricia S. Goldman-Rakic \\ Section of Neurobiology, Yale University School of Medicine, New Haven, Connecticut 06510
}

The prominent role of the prefrontal cortex (PFC) in working memory (WM) is widely acknowledged both in nonhuman primates and in humans. However, less agreement exists on the issue of functional segregation within different subregions of the PFC with regard to the domains of spatial and nonspatial processing or involvement in simpler versus more complex aspects of WM, e.g., maintenance versus processing function. To address these issues, six monkeys were trained to perform four WM tasks that differed with respect to domain (spatial vs nonspatial) and level of WM demand (recall of one vs three items). The delayed response format was used to assess simple one-item memory, whereas self-ordering tasks were used to require the monkey to maintain and organize three items of information within WM. After training, the monkeys received bilateral PFC lesions in one of two different areas, Walker's areas 9 and $8 \mathrm{~B}$ (dorsomedial convexity; $n=3$ ) or areas 46 and $8 \mathrm{~A}$ (dorsolateral cortex, $n=3$ ) and then tested postoperatively on all tasks.

It is widely accepted that the prefrontal cortex (PFC) plays a major role in the most sophisticated aspects of human thought, including reasoning and planning. These functions of metacognition may greatly depend on more fundamental cognitive operations, namely the working memory (WM) processes defined by the ability to maintain, manipulate, and use mental representations for goal-directed behavior (Baddeley, 1996; GoldmanRakic, 1987). Experimental studies in nonhuman primates and more recent functional imaging studies in humans have underlined the critical role played by the prefrontal cortex in WM (for review, see Goldman-Rakic, 1987, 1995; Owen, 1997; Ungerleider et al., 1998). However, unresolved issues with particular relevance to human cognition include whether the PFC's role in WM functions is that of a scratch-pad for temporary storage of information or a nondenominational central processor and whether these key aspects of WM are dissociable and how they might be distributed within the PFC. Two models of functional segregation of the PFC have been proposed. One model, developed by Goldman-Rakic and colleagues (Goldman-Rakic, 1987; Fu-

Received Nov. 30, 1998; revised March 29, 1999; accepted April 6, 1999.

This work was supported by grants from Fyssen and Philippe Fondations and Servier to R.L. and by National Institutes of Health Grant MH 38546 and EJLB Foundation grants to P.G.-R.

Correspondence should be addressed to Dr. Patricia S. Goldman-Rakic, Section of Neurobiology, Yale University School of Medicine, 333 Cedar Street, New Haven, CT 06510.

Dr. Levy's present address: Federation de Neurologie and Institut National de la Santé et de la Recherche Médicale U.289, Hopital de la Salpetriere, 75013 Paris, France.

Copyright () 1999 Society for Neuroscience $0270-6474 / 99 / 195149-10 \$ 05.00 / 0$
Monkeys with lesions of the dorsomedial convexity were not impaired either on spatial or nonspatial WM tasks, whether the task required simple storage or sequential processing. By contrast, lesions of the dorsolateral cortex produced a significant and persistent impairment in both simple and complex spatial WM but no impairment in the two nonspatial WM tasks. These results support a functional segregation within the dorsolateral prefrontal cortex for WM: the dorsolateral prefrontal cortex (area 46/8A) is selectively involved in spatial WM, whereas the dorsomedial convexity (area $9 / 8 \mathrm{~B}$ ) is not critically engaged in either spatial or nonspatial working memory. Furthermore, the specific involvement of area 46/8A in spatial sequencing as well as in single-item storage WM tasks supports, in the nonhuman primate, an areal dissociation based on domain rather than on processing demand.

Key words: rhesus monkey; delayed response; self-ordered tasks; cortical lesion; working memory; cognition

nahashi et al., 1993; Wilson et al., 1993; O’Scalaidhe et al., 1997), postulates a modular organization of WM based on the domain of information processing (the "domain specificity" model). In this view, the cortex surrounding the principal sulcus (Walker's area 46) is specialized for "on-line" processing of information concerning the location of objects, whereas cortices below area 46the inferior convexity (Walker's areas 12 and 45) - are involved in processing the features and identity of objects within WM. In this theoretical framework, "domain" embraces any sensory modality that registers information relevant to that domain, e.g., visual and auditory signals can provide input to a spatial domain. The second model, proposed by Petrides and Owen (Petrides et al., 1993; Petrides, 1995; Owen et al., 1996a,b, 1998; Owen, 1997), postulates a segregation within the PFC based on the level of processing within WM ("operation-segregation" model). In this model, the PFC is divided into two regions that are referred to, respectively, as the mid-frontal cortex (in monkeys, middle portions of Walker's area 9 and the rim of area 46) and the inferior convexity (the lower portion of area 46 and Walker's areas 12/45). According to Owen (1997), the mid-lateral or dorsomedial convexity (our terminology) is viewed as an executive processor that allows active manipulation and monitoring of information within WM. By contrast, the inferior convexity is involved in lower demand processing such as maintenance of information in WM. According to the operation-segregation view, different levels of processing are segregated across prefrontal areas in a hierarchical scheme, whereas in the domain-specific model, different levels of processing within a given domain may be performed within the same region, possibly engaging different numbers of cellular pro- 
cessing units (columns) within that region to accommodate different processing demands.

To obtain further information on these issues, the aim of the present study was to determine the critical level of anatomicalfunctional segregation for WM within the PFC. Toward this end, monkeys were trained to perform WM tasks varying with respect to sensory domain (spatial vs nonspatial) and level of processing (simple vs complex WM processing). The complex WM tasks used in this study were "self-ordered tasks" (Petrides and Milner, 1982; Petrides et al., 1993; Petrides, 1995). These tasks differ from the classic delayed response tasks in that the memory load is higher (three items vs one item), and in addition the subject must extract and arrange the relevant mental representations into a coherent temporal sequence. Once the monkeys reached criterion performance levels on these tasks, they received bilateral resections of the dorsomedial (DM) convexity (areas 9 and $8 \mathrm{~B}$ ) or the middle dorsolateral (DL) region (areas 46 and 8A). If segregation in the PFC is based on sensory domain, we expect lesions of areas 46/8A to produce a selective spatial WM deficit. Alternatively, if the DM or DL cortex contains the executive processor, lesions of one or both areas should produce a supra-domain deficit, particularly in both self-ordering tasks, which tap the more complex processing functions of WM.

A preliminary report of these data has been published previously in abstract form (Levy and Goldman-Rakic, 1997).

\section{MATERIALS AND METHODS}

\section{General procedure}

All animals included in this study were first trained to perform four different WM tasks (two spatial and two nonspatial) at a stable and high level of performance. They were then assigned to receive a bilateral aspiration lesion of either the DM or DL region of the PFC. The monkeys were tested again on all tasks after surgery. Postoperative performance of each group was compared with its preoperative performance ("within-group" comparison) and with each other ("betweengroup" comparison).

\section{Animals}

Six adult rhesus monkeys (Macaca mulatta), four males and two females (one in each of the two groups), were able to complete the study. These animals were housed in separate cages in animal rooms under standard conditions of temperature, relative humidity, air exchange, and day/night cycles. They were fed a diet of monkey chow and fruit adjusted to maintain a stable level of performance. Water was available ad libitum. This study was performed in accordance with the Guide for the Care and Use of Laboratory Animals adopted and promulgated by the National Institutes of Health. All procedures were approved by the Yale Animal Care and Use Committee.

\section{Preoperative training}

Behavioral tasks. The four tasks were given in the following order: (1) spatial delayed response (SDR) task, (2) three-position self-ordered (POS-SO) task, (3) delayed object nonmatching-to-sample (DNMTS) task, and (4) three-object self-ordered (OBJ-SO) task. Monkeys were first habituated to a Wisconsin General Testing Apparatus (WGTA), in which they moved freely. The testing sessions in the WGTA were given in a darkened and sound-shielded room with a background of $80 \mathrm{~dB}$ white noise. An opaque sliding screen separated the monkey's compartment from a test tray during the delay periods of each task and between intertrial intervals. Correct choices were reinforced with preferred rewards (halved peanuts, raisins, or small slices of apple). Incorrect choices were not reinforced. Monkeys were trained to perform 20 trials per session for the SDR and DNMTS tasks and 10 trials per session for the POS-SO and OBJ-SO tasks. In all tasks, monkeys received one session per day, $5 \mathrm{~d}$ per week.

Spatial delayed response task. The training on the SDR task was performed in several steps (Goldman, 1971). Initially, a brief delay (1 sec) was interposed between the baiting and the response. Once the monkey achieved a criterion of 18 or more correct out of the 20 trials

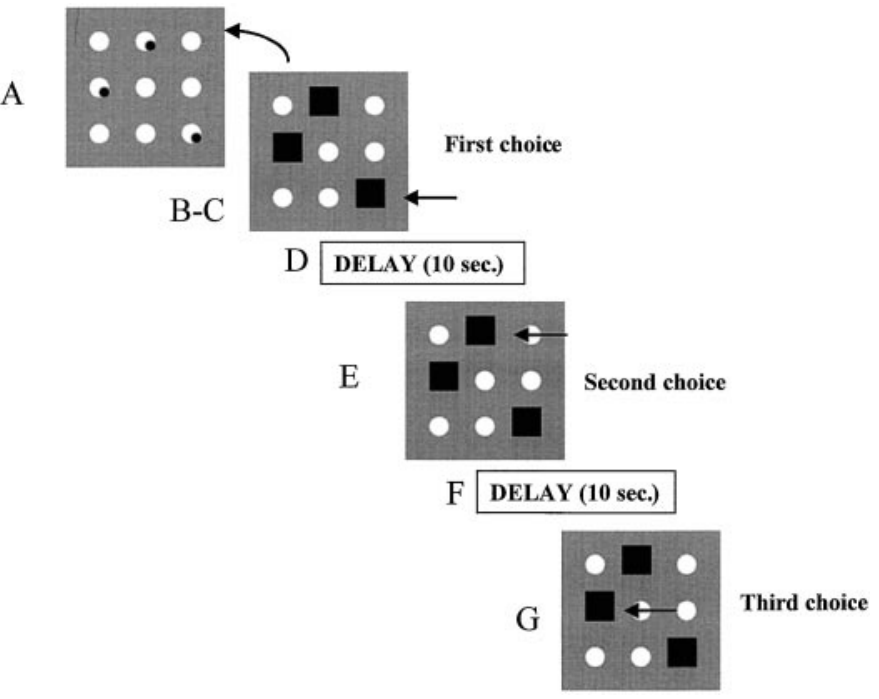

Figure 1. POS-SO task. $A$, The monkey views a testing tray with nine food wells, three of which are covered by identical blue plaques, each plaque covering a reward. $B$, The monkey is allowed to displace any one of the three plaques to retrieve a reward. $C$, An opaque screen is lowered for a $10 \mathrm{sec}$ delay period during which the plaque is replaced over the empty well $(D)$. After this first delay, the monkey is allowed to make his second choice by displacing any of the three plaques; $(E)$ however, to receive a reward, he must choose one of the two remaining plaques that cover baited wells. After the second choice, the opaque screen is again lowered for a second $10 \mathrm{sec}$ delay period. To complete the trial, the monkey has to displace the one remaining plaque over the food well that still contains a reward $(G)$. The trial is completed only when the monkey has found all rewards. Thus, a trial could consist of a minimum of three choices, but choice of an incorrect food well prolongs the current trial until all rewards are retrieved (all choices being separated from each other by a $10 \mathrm{sec}$ delay). Monkeys receive 10 trials per day. Plaques are positioned pseudorandomly to discourage the monkeys from adopting spatial strategies.

( $90 \%$ correct responses in one session), the length of the delay period was gradually increased to 3 and $5 \mathrm{sec}$. At $5 \mathrm{sec}$, monkeys had to reach a performance criterion of 90 correct responses in 100 trials (i.e., a mean of $90 \%$ correct responses over five consecutive sessions). The delay period was then increased to $10 \mathrm{sec}$, and performance criterion was set at $90 \%$ or more correct responses over 5 consecutive days. Monkeys failing to reach this level of performance after 500 trials ( 25 sessions) were rejected from the study.

Delayed object nonmatching-to-sample task. Monkeys were trained on an object-unique version of the DNMTS task (Bachevalier and Mishkin, 1986). The delay period was $10 \mathrm{sec}$. Twenty trials were given each day. New objects were selected from a set of 1000 objects. All animals were trained to the criterion of 90 or more correct responses in 100 trials (i.e., a mean of $90 \%$ correct responses over five consecutive sessions). Monkeys failing to reach this level of performance after 500 trials (25 sessions) were rejected from the study.

Three-position self-ordered task. In the final phase of the POS-SO task, the monkey confronted a test tray containing nine food wells, spaced 4 $\mathrm{cm}$ from each other, arranged in three arrays of three wells (Fig. 1). Three identical blue plaques $(5.5 \mathrm{~cm}$ square) were placed on three of the nine food wells, each plaque covering a reward. The monkey was then allowed to displace any one of the three plaques and to retrieve the reward underneath. The opaque screen was then lowered for a $10 \mathrm{sec}$ delay period, during which time the displaced plaque was replaced but the food well was not rebaited. After this first delay, the monkey was allowed to make a second choice by displacing any of the three plaques. However, to find a reward, the animal had to choose from one of the two food wells that had not been chosen previously. After the second choice, the opaque screen was lowered again for a second $10 \mathrm{sec}$ delay period. To complete the trial, after the delay, the monkey had to correctly locate the only remaining well that still contained a reward. The trial was completed only when the monkey had found all rewards. Thus, a trial could be 


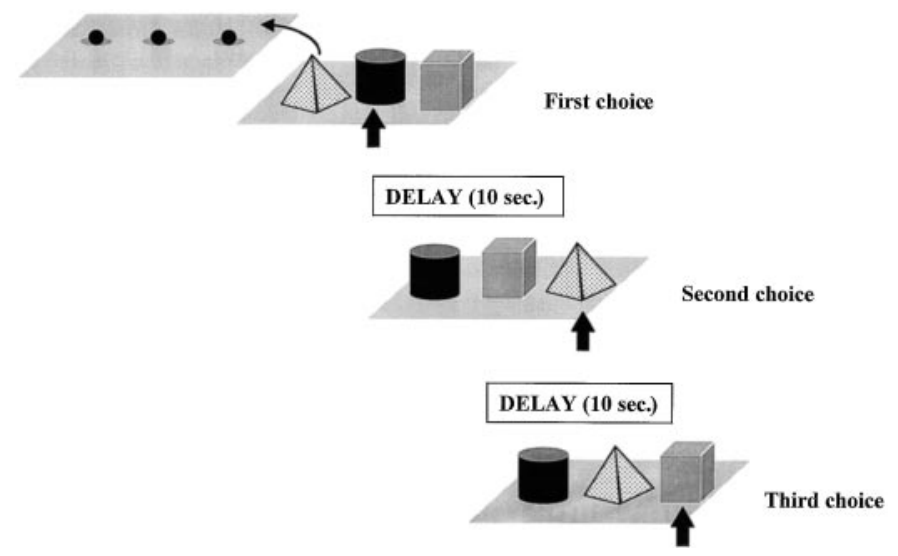

Figure 2. OBJ-SO task. The test tray contains three food wells, each covered by an object distinctive for shape, color, and size and each containing a reward. New sets of three objects were used on each trial. The testing procedure was similar to the POS-SO task except that the position of the object was changed pseudorandomly during the delay periods. Monkeys received 10 trials per day.

completed in three steps, and the choice of a nonrewarded plaque prolonged the trial until all rewards were retrieved (all choices being separated from each other by a $10 \mathrm{sec}$ delay). Monkeys received 10 trials per day. The plaques were positioned pseudorandomly to prevent automatic spatial strategies of retrieval. Eighty-three different combinations were possible. Performance was evaluated on six parameters: (1) the number of correct second choices per session, (2) the number of correct third choices per session, (3) the number of correct second and third choices per session, (4) the number of correct sequences per session (i.e., the number of trials when the first, second, and third choices were consecutively correct), (5) the total number of choices per session, and (6) the number of perseverative errors per session (i.e., the number of errors made by consecutively choosing the same plaque). The probability of being correct by chance on the first trial is $100 \%$. It decreases to $66.6 \%$ by the second choice and to $33.3 \%$ by the third choice. The probability of being correct by chance for a whole sequence is the probability of being correct by chance on the third choice, having been correct by chance on the second choice (i.e., one-third $\times$ two-thirds), which is $44.4 \%$. Criterion was $90 \%$ or more for combined second and third correct choices (i.e., 18 or more correct out of 20 choices per session) on 5 consecutive days. This criterion had to be reached within 25 consecutive sessions ( 250 trials) at $10 \mathrm{sec}$ delay. If a monkey failed to reach criterion, 10 more sessions were given and the criterion was lowered to $85 \%$. Monkeys failing to reach this criterion were eliminated from the study.

Monkeys learned this task in several phases, starting with a simple version of the task. In the first version, the monkey performed the task with two plaques without the screen being lowered and raised between choices. The delay period was then introduced, starting with swift lowering and raising of the opaque screen and progressively increasing the delay period to $10 \mathrm{sec}$. Once this task was acquired, the POS-SO task was introduced, again with a progressive increase of the delay period. For both tasks, criterion was $90 \%$ correct responses for 5 consecutive days at 5 and $10 \mathrm{sec}$ delay periods. For other intermediate delay periods, the criterion was $90 \%$ correct responses in one session. Monkeys failing to reach criterion within 25 sessions at any of these steps were eliminated from the study.

Three-object self-ordered task. The OBJ-SO task is based on that introduced by Petrides (1995). In the final stage of training (Fig. 2), the general format of the task is identical to the POS-SO task described above. The main difference between the OBJ-SO and POS-SO tasks was that in the former, the relevant choices were based on the physical attributes of objects (they differed by shape, color, and size) and not on their position. Thus, to prevent the monkeys from adopting a strategy of retrieval based on position, the location of objects was changed on each trial after a pseudorandom order. Monkeys received 10 trials per day. Three different objects from the 1000 member set were used on each trial. Because the combination of objects was randomized at the beginning of each session, the probability of encountering the same combination twice was virtually zero. Objects were first presented to the monkeys before testing began, and those provoking a fear reaction were not used in the task. Performance was assessed on the same six parameters used in the POS-SO task (see above). The probabilities of being correct by chance are identical to those described for the POS-SO task. All animals were trained to the criterion of $90 \%$ correct on cumulative second and third choice scores over five consecutive sessions (i.e., 90 or more correct out of 100 choices) within 25 sessions (250 trials). If a monkey failed to reach this criterion, 10 more sessions were given and the criterion was lowered at $85 \%$. Monkeys failing to reach this criterion were eliminated from the study.

Monkeys learned this task in several phases starting with a simple version of the task. On the first version, they had to perform a two-object self-ordered task. In this task, using a two-well board, the monkeys had to self-order their choices between two different objects. The delay period between the first and second choice was progressively increased to $10 \mathrm{sec}$. Once this task was acquired, the OBJ-SO task was introduced, again with a progressive increase of the delay period. Criterion was $90 \%$ correct responses for 5 consecutive days at 5 and $10 \mathrm{sec}$ delay periods. For other intermediate delay periods, the criterion was $90 \%$ correct responses in one session. Monkeys failing to reach criterion within 25 sessions at any of these steps were eliminated from the study.

\section{Surgery}

Animals were restrained using ketamine $(10 \mathrm{mg} / \mathrm{kg})$ and atropine sulfate $(0.2 \mathrm{mg} / \mathrm{kg})$. After intravenous catheterization, a flash injection $(50$ $\mathrm{mg} / \mathrm{ml}$ ) of sodium pentobarbitol was followed by continual perfusion throughout the procedure. One-stage bilateral aspiration lesions were made under aseptic conditions. The monkeys were divided into two groups. Group DL $(n=3$; two males and one female) received lesions of area 46 and anterior $8 \mathrm{~A}$, intended to include the lips, banks, and depths of the principal sulcus throughout its entire extent and the cortex anterior to the arcuate sulcus as well as the adjacent cortices up to $5 \mathrm{~mm}$ below and above the principal sulcus. The second group $(n=3$; two males and one female) received DM lesions of areas 9 and $8 \mathrm{~B}$, starting $\sim 5 \mathrm{~mm}$ above the principal sulcus and including the entire Walker's area 9, sparing the frontopolar cortex rostrally and Brodmann's area 6 caudally.

\section{Postoperative phase}

After surgery, monkeys were given 2 weeks of recovery followed by a postoperative training phase in which they were tested on the same four tasks as before lesions. Testing used the $10 \mathrm{sec}$ delay version of each of the four tasks. The order of tasks was identical to that used in the preoperative phase. Monkeys were trained to criteria (i.e., five consecutive sessions at $90 \%$ correct responses) or 25 sessions on each task, whichever came first.

\section{Histology}

At the end of the experiments, the animals received a lethal dose of sodium pentobarbitol, administered intravenously. They were then perfused transcardially with $4 \%$ paraformaldehyde. The brain was removed from the skull and fixed in formalin, before being blocked and processed. Coronal sections and surface reconstruction of the lesions for each case are illustrated in Figures 3 and 4.

\section{Analysis of results}

The results were analyzed in two ways. The first compared performance before and after the lesion in each group separately (within group comparison). The second analysis compared postoperative performance between the two groups of lesioned monkeys (between groups comparison). In both analyses, group performance was the mean of the five best consecutive sessions.

Statistical analyses for the between-groups comparison were performed using one-factor ANOVA (Statview 4.5, Abacus Concept) with lesion group (DM and DL) as the factor. Within-group comparison was performed using two-tailed paired $t$ tests (Statview 4.5, Abacus Concept). This analysis was used to compare the performance before and after lesions in each group. All data are presented as the mean \pm SEM. The null hypothesis was rejected at an $\alpha$ risk of $5 \%$.

\section{RESULTS}

\section{Preoperative performances}

Animals were assigned to lesion groups in advance of preoperative training. Only the monkeys who reached criterion perfor- 
Figure 3. Lateral view reconstructions of the dorsolateral $(D L)$ prefrontal cortex lesions and coronal drawings illustrating the extent of the lesions. The lesion is represented in black on the lateral views. The boundaries of the lesions are indicated by the bold black lines on five selected coronal sections. DL1, $D L 2$, and $D L 3$ refer to individual monkeys.

\section{DL1}

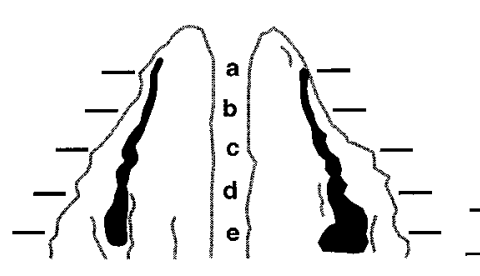

a

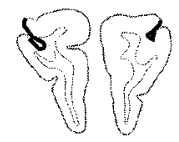

b
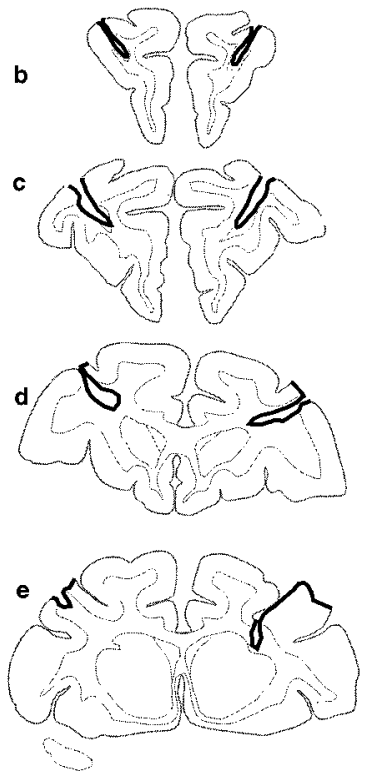

DL2

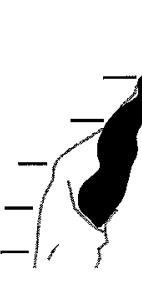

a

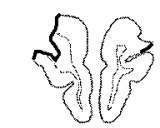

b

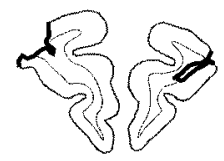

c
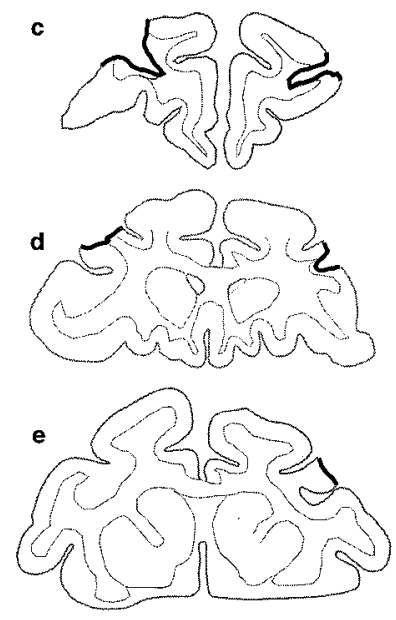

DL3

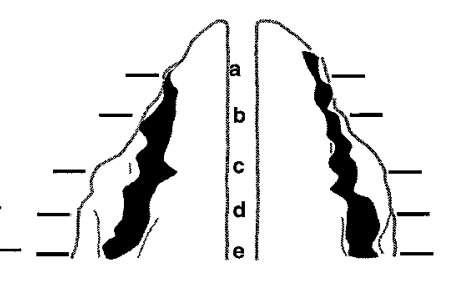

a
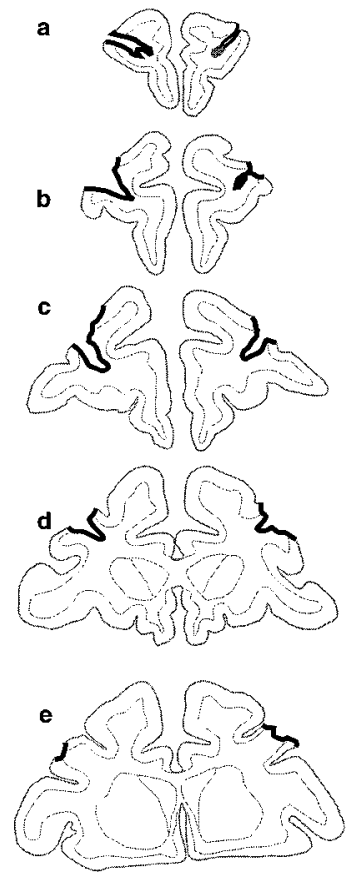

mance on all tasks were included in the lesion groups. There were no differences in preoperative performance scores between groups on any of the four WM tasks (Tables 1, 2). All monkeys were first trained on the simple storage WM task, i.e., the SDR task. Because the tasks that were presumed to be more difficult (self-ordered tasks) were learned after the SDR task, their acquisition might have been facilitated by the learning of the simple WM tasks that preceded them. It is thus not possible to use the number of days to criterion for each task as an index of difficulty. However, it should be noted that three monkeys who reached criterion on the SDR task had to be eliminated from the study because they were unable to reach criterion on the POS-SO task, supporting the assumption that the latter task was more difficult because of its higher storage/processing demands.

\section{Postoperative performance SDR task (Fig. 5)}

The monkeys with DL lesions were significantly and markedly impaired both compared with preoperative performance (percentage of correct responses \pm SEM, before lesions: $91.36 \pm 0.90$; after lesions: $66 \pm 7.18, p<0.05)$ and relative to the DM group $\left(F_{(1,4)}=46,7, p<0.005\right)$. Furthermore, the DL group showed no evidence of improvement over the course of testing (one-factor ANOVA with repeated measures with trials as the factor and the number of correct sequences as the dependent measure: $F_{(2,24)}=$ 1.29, $p=0.22$ ) (also see Fig. 6). By contrast, DM monkeys performed above the $90 \%$ level postoperatively $(93.41 \pm 2.09)$, and this performance did not differ significantly from preoperative performance $(p=0.88)$.

\section{DNMTS task (Fig. 5)}

The DL lesion group was neither impaired nor improved as compared with the preoperative phase $(92.00 \pm 1.73$ vs $94.67 \pm$ $2.33, p=0.18)$ and did not differ from the DM group $\left(F_{(1,4)}=\right.$ $0.23, p=0.66)$. The DM group performed significantly better postoperatively than preoperatively $(96.00 \pm 1.53$ vs $91.67 \pm 1.53$, $p=0.02$ ). There was no difference between lesion groups in the number of sessions necessary to reach criterion in the postoperative phase.

\section{POS-SO task (Table 1, Fig. 7)}

DL lesions produced a sharp drop in performance compared with preoperative performance $(p<0.05)$ for all measures except for the percentage of correct second choices $(p=0.13)$. Furthermore, DL monkeys performed significantly more poorly than the DM group, on all of the six performance measures $\left(F_{(1,4)}>7.8\right.$, $p<0.05$, on all measures). To determine whether the DL monkeys improved with postoperative experience, we performed an analysis on the postoperative performance scores throughout the 25 postoperative sessions using a one-factor ANOVA with daily performance as the factor. The result indicated that the performance of the DL group improved in the course of postoperative testing $\left(F_{(2,24)}=2,2, p=0.01\right)$. However, it is important to note that none of the monkeys in this group were able to reach 


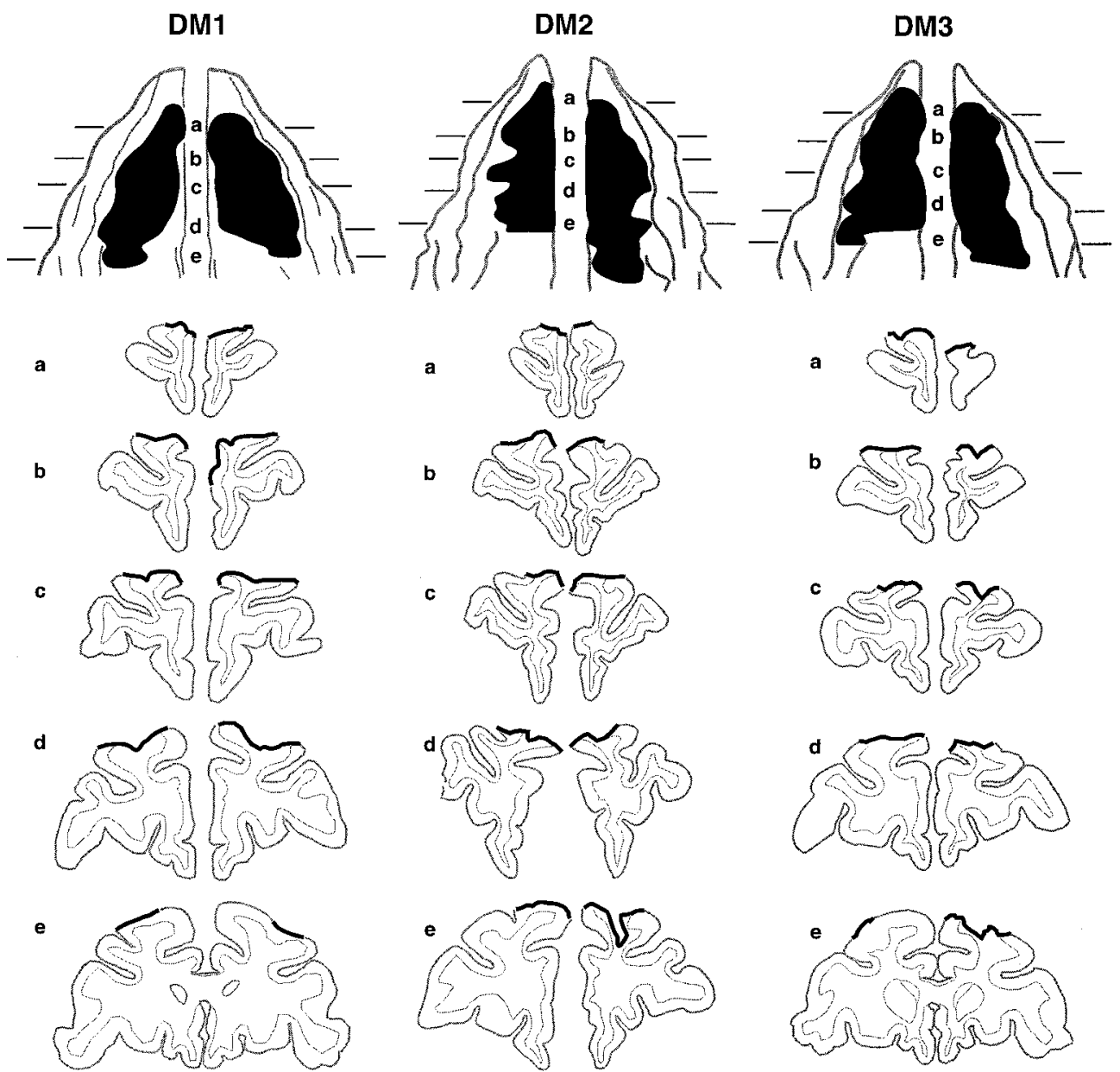

Figure 4. Extent of the dorsomedial $(D M)$ prefrontal cortex lesions (for a description of the diagrams, see legend of Fig. 3). DM1, DM2, and DM3 refer to the three monkeys given DM lesions. criterion on any of the six measures. By contrast, monkeys with lesions of the DM region performed as well postoperatively as preoperatively on this task ( $p>0.05$ for all measures) (Table 1 , Fig. 7). However, two of the three monkeys with DM lesions (DM1 and DM2) showed a slight decrement in performance after surgery on one of the six measures-the percentage of correct sequences (DM1: before lesions, $86 \pm 2.45$, after lesions, $78 \pm 3.74$; DM2: before lesions, $82 \pm 5.83$, after lesions, $70 \pm 7.07)$.

\section{OBJ-SO task (Table 2, Fig. 7)}

No significant differences were found between preoperative and postoperative performance in the DM group (in all measures, $p>$ 0.05 ) or the DL group (in all measures, $p>0.05$ ). DL and DM groups did not differ from one another, although monkeys generally performed somewhat more poorly on all measures postoperatively (in all measures, $F_{(1,4)}<2, p>0.05$ ).

\section{DISCUSSION}

The present study demonstrates a functional dissociation between the dorsomedial and dorsolateral PFC with respect to WM processes. Only lesions of dorsolateral areas 46/8A impaired WM processes, whereas lesions of the dorsomedial areas $9 / 8 \mathrm{~B}$ were without lasting consequences. Second, the deficit after the dorsolateral lesion was confined to the spatial domain and did not encompass object WM. Finally, the findings revealed that dorsolateral cortical areas are no less critical for tasks with low WM demand than for more complex sequential processing with higher WM load. These results support an anatomical-functional seg- regation of the PFC for $\mathrm{WM}$ based on the type of information being processed rather than on the nature of the operations performed.

\section{Processes and brain regions engaged in the SDR and DNMTS tasks}

DL lesions produced a severe and stable impairment on the SDR task, whereas monkeys with lesions of the DM convexity exhibited either a transient impairment or performed as well as they did preoperatively. Both findings are in accord with numerous studies demonstrating that lesions of dorsolateral PFC, and more specifically those restricted to the principal sulcus and the middle third of its sulcus (Butters and Pandya, 1969; Butters et al., 1971, 1972, Goldman-Rakic, 1987; Fuster, 1989), are sufficient to produce a deficit as severe as larger PFC lesions. In contrast, neither spatial delayed response nor delayed alternation deficits are observed after lesions of either the adjacent dorsomedial cortex (Goldman, 1971) or the inferior convexity cortex (Mishkin and Manning, 1978; Passingham, 1985). Collectively, these findings confirm the critical role of the principal sulcal region in the most elementary WM operation within the spatial domain, i.e., the on-line maintenance and use of mental representations for simple actions based on binary choice.

The DNMTS task is used to measure recognition memory. Although recognition memory refers to the ability to form lasting traces and requires medial temporal cortical regions (Mishkin and Murray, 1994), this task can also be viewed as a low-demand WM task. Indeed, in the DNMTS task, the monkey has to keep 
Table 1. Preoperative and postoperative performances on the POS-SO in the two groups of monkeys

\begin{tabular}{|c|c|c|c|c|c|c|c|c|c|c|c|c|}
\hline & \multicolumn{2}{|c|}{ Correct $2+3(\%)$} & \multicolumn{2}{|c|}{ Correct sequences $(\%)$} & \multicolumn{2}{|c|}{ Correct second $(\%)$} & \multicolumn{2}{|c|}{ Correct third $(\%)$} & \multicolumn{2}{|c|}{ Total of choices (1) } & \multicolumn{2}{|c|}{ Perseverative errors (2) } \\
\hline & $\begin{array}{l}\text { Before } \\
\text { lesion }\end{array}$ & $\begin{array}{l}\text { After } \\
\text { lesion }\end{array}$ & $\begin{array}{l}\text { Before } \\
\text { lesion }\end{array}$ & $\begin{array}{l}\text { After } \\
\text { lesion }\end{array}$ & $\begin{array}{l}\text { Before } \\
\text { lesion }\end{array}$ & $\begin{array}{l}\text { After } \\
\text { lesion }\end{array}$ & $\begin{array}{l}\text { Before } \\
\text { lesion }\end{array}$ & $\begin{array}{l}\text { After } \\
\text { lesion }\end{array}$ & $\begin{array}{l}\text { Before } \\
\text { lesion }\end{array}$ & $\begin{array}{l}\text { After } \\
\text { lesion }\end{array}$ & $\begin{array}{l}\text { Before } \\
\text { lesion }\end{array}$ & $\begin{array}{l}\text { After } \\
\text { lesion }\end{array}$ \\
\hline DM1 & 93 & 89 & 86 & 78 & 98 & 100 & 88 & 78 & 22.6 & 24.8 & 0.2 & 0.4 \\
\hline DM2 & 91 & 85 & 82 & 70 & 98 & 96 & 84 & 74 & 22.2 & 24.2 & 0.8 & 1.2 \\
\hline DM3 & 89 & 89 & 78 & 78 & 96 & 100 & 82 & 78 & 24.2 & 23.0 & 2.4 & 0.6 \\
\hline Mean \pm SEM & $91.00 \pm 1.55$ & $87.67 \pm 1.33$ & $82.00 \pm 2.31$ & $75.33 \pm 2.67$ & $97.33 \pm 0.67$ & $98.67 \pm 1.33$ & $84.67 \pm 1.76$ & $76.67 \pm 1.33$ & $23.00 \pm 0.61$ & $24.53 \pm 0.18$ & $1.13 \pm 0.66$ & $0.73 \pm 0.24$ \\
\hline DL1 & 91 & 81 & 82 & 62 & 96 & 90 & 86 & 72 & 22.6 & 27.4 & 1.4 & 4.6 \\
\hline DL2 & 93 & 70 & 86 & 42 & 100 & 82 & 86 & 64 & 22.0 & 30.4 & 0.0 & 5.6 \\
\hline DL3 & 91 & 75 & 82 & 50 & 96 & 90 & 86 & 58 & 23.0 & 28.2 & 0.0 & 4.8 \\
\hline
\end{tabular}

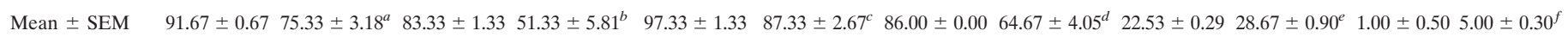

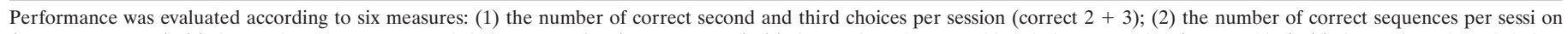

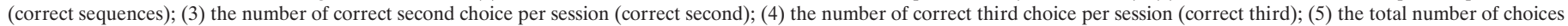

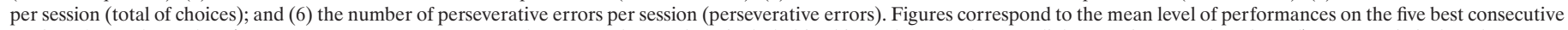

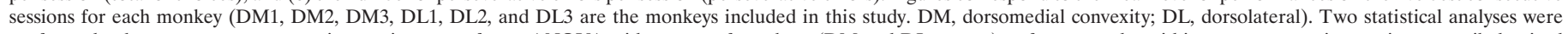

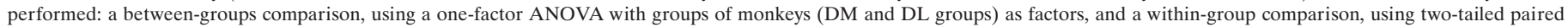

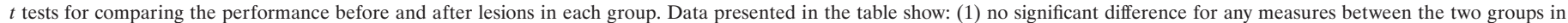

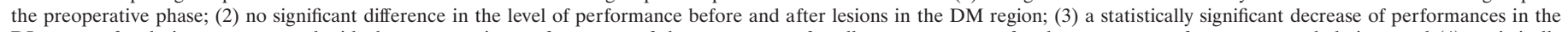

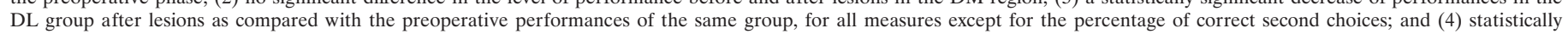
significant lower performances in the DL group as compared with the DM group.

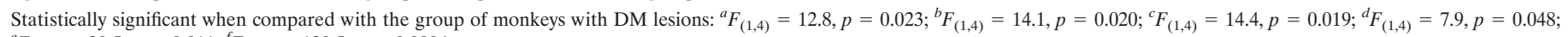
${ }^{e} F_{(1,4)}=20.5, p=0.011 ;{ }^{f} F_{(1,4)}=120.5, p=0.0004$.

Statistically significant when compared with the preoperative phase: ${ }^{a} p=0.049 ;{ }^{b} p=0.044 ;{ }^{d} p=0.034 ;{ }^{e} p=0.033 ;{ }^{f} p=0.038$.

Not significant when compared with the preoperative state: ${ }^{c} p=0.13$.

Table 2. Preoperative and postoperative performances on the OBJ-SO in the two groups of monkeys

\begin{tabular}{|c|c|c|c|c|c|c|c|c|c|c|c|c|}
\hline & \multicolumn{2}{|c|}{ Correct $2+3(\%)$} & \multicolumn{2}{|c|}{ Correct sequences $(\%)$} & \multicolumn{2}{|c|}{ Correct second (\%) } & \multicolumn{2}{|c|}{ Correct third (\%) } & \multicolumn{2}{|c|}{ Total of choices $(\mathrm{A})$} & \multicolumn{2}{|c|}{ Perseverative errors (B) } \\
\hline & $\begin{array}{l}\text { Before } \\
\text { lesion }\end{array}$ & $\begin{array}{l}\text { After } \\
\text { lesion }\end{array}$ & $\begin{array}{l}\text { Before } \\
\text { lesion }\end{array}$ & $\begin{array}{l}\text { After } \\
\text { lesion }\end{array}$ & $\begin{array}{l}\text { Before } \\
\text { lesion }\end{array}$ & $\begin{array}{l}\text { After } \\
\text { lesion }\end{array}$ & $\begin{array}{l}\text { Before } \\
\text { lesion }\end{array}$ & $\begin{array}{l}\text { After } \\
\text { lesion }\end{array}$ & $\begin{array}{l}\text { Before } \\
\text { lesion }\end{array}$ & $\begin{array}{l}\text { After } \\
\text { lesion }\end{array}$ & $\begin{array}{l}\text { Before } \\
\text { lesion }\end{array}$ & $\begin{array}{l}\text { After } \\
\text { lesion }\end{array}$ \\
\hline DM1 & 91 & 90 & 82 & 80 & 100 & 100 & 82 & 80 & 22.8 & 22.4 & 1.4 & 0.4 \\
\hline $\mathrm{DM} 2$ & 91 & 92 & 82 & 84 & 98 & 98 & 84 & 86 & 22.0 & 21.6 & 0.2 & 0.6 \\
\hline DM3 & 91 & 90 & 82 & 80 & 100 & 100 & 82 & 80 & 22.4 & 22.6 & 0.4 & 0.6 \\
\hline Mean \pm SEM & $91.00 \pm 0.00$ & $90.67 \pm 0.67$ & $82.00 \pm 0.00$ & $81.33 \pm 1.33$ & $99.33 \pm 0.67$ & $99.33 \pm 0.67$ & $82.67 \pm 0.67$ & $82.00 \pm 2.00$ & $22.4 \pm 0.23$ & $22.2 \pm 0.30$ & $0.67 \pm 0.37$ & $7 \quad 0.53 \pm 0.07$ \\
\hline DL1 & 96 & 91 & 92 & 82 & 100 & 98 & 92 & 84 & 21.4 & 22.4 & 0.8 & 0.4 \\
\hline DL2 & 91 & 90 & 82 & 80 & 96 & 98 & 86 & 82 & 22.4 & 22.6 & 0.8 & 0.8 \\
\hline DL3 & 87 & 81 & 74 & 62 & 92 & 86 & 82 & 76 & 22.4 & 26.6 & 1.2 & 4 \\
\hline Mean \pm SEM & $91.33 \pm 2.60$ & $87.33 \pm 3.18$ & $82.67 \pm 5.21$ & $74.67 \pm 6.36$ & $96.00 \pm 2.31$ & $94.00 \pm 4.00$ & $86.67 \pm 2.90$ & $80.67 \pm 2.40$ & $22.07 \pm 0.33$ & $23.87 \pm 1.37$ & $0.93 \pm 0.13$ & $31.73 \pm 1.14$ \\
\hline
\end{tabular}

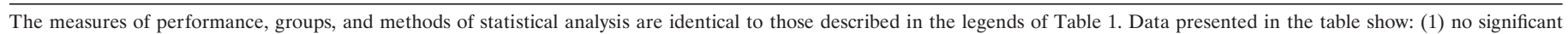

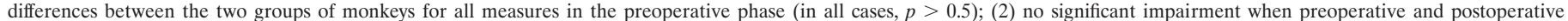

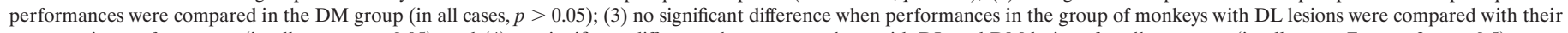
preoperative performances (in all cases, $p>0.05$ ); and (4) no significant difference between monkeys with DL and DM lesions for all measures (in all cases, $F_{(1,4)}<2, p>0.5$ ).

"in mind" the previous nonrelevant stimulus. In the present study, neither monkeys with DM nor those with DL lesions were impaired on a trial-unique version of DNMTS. Similar results have been reported previously for matching or nonmatching-to-sample tasks (Stamm and Rosen, 1973; Passingham, 1975; Mishkin and Manning, 1978; Bachevalier and Mishkin, 1986). Thus, there is little evidence to indicate a role of either the DM or DL prefrontal sectors in object recognition or in basic short-term memory for object features. In contrast, impairments in performance of DNMTS tasks have been reported after lesions of the inferior convexity (Mishkin and Manning, 1978; Kowalska et al., 1991) or ventromedial prefrontal lesions (Bachevalier and Mishkin; 1986, Meunier et al., 1997). Although the nature of the underlying impairment after such lesions remains elusive, a WM deficit specific to features of objects could account for the behavioral impairments observed after inferior prefrontal lesions. Recent electrophysiological studies have revealed that neurons in these regions are highly responsive to visual stimulation and to the recall of objects or faces and are unresponsive in SDR tasks (Wilson et al., 1993; O’Scalaidhe et al., 1997, 1999).

\section{Processes and brain regions engaged in the SO tasks}

The SO tasks, used originally in frontal lobe patients by Petrides and Milner (1982), require the subject to monitor the order of items in short-term memory. In the present study, we used a nonspatial SO task (OBJ-SO) based on Petrides (1995) and designed a new spatial version (POS-SO) expressly for this study. The SO tasks require the same basic WM processes engaged by the SDR task (i.e., maintenance and use of internal representations). However, they impose a larger memory load (three items vs one) than do the DR tasks, and the monkey also has to compare his current choice with previous choices, i.e., it has to serially self-order internal representations. This additional monitoring process is conceptually an important upgrade in the level of processing over the classic DR tasks, requiring a supplementary executive operation. 
A. SDR task

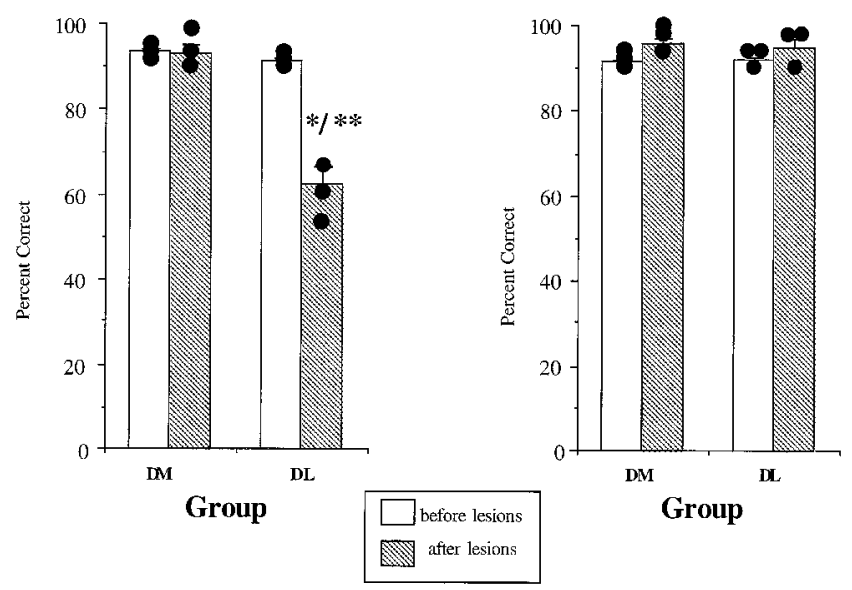

Figure 5. Mean percentage correct response in the SDR and DNMTS tasks in the two groups of monkeys before and after lesions. Solid circles indicate the score of each monkey in each group. $D M$, Dorsomedial group; $D L$, dorsolateral group. *Statistically significant $(p<0.05)$ withingroup comparison; ** statistically significant $(p<0.005)$ between-group comparison.

DL lesions produced a profound and persistent impairment in the POS-SO task. Because the POS-SO task requires the same basic WM processing as the SDR task, it is not possible to determine, from our study, the contribution to this deficit of the additional components that differentiate the POS-SO task from the SDR task. However, all monkeys with DL lesions were impaired even at the second choice, a condition that is less demanding than the SDR format because the probability of being correct by chance is higher than in the SDR task. These results suggest that difficulties in the POS-SO task could be attributed, in large part, to the short-term memory deficit responsible for the SDR task. This would favor a role of the DL area both in elementary WM operations (maintenance) and in more executive operations (self ordering), and indeed, the maintenance of single items in short-term memory is a constituent operation of sequential processing. An alternative interpretation of these data is that the dorsolateral region is mainly involved in storing spatial information, whereas another area of the PFC may be selectively involved in the executive aspects of WM. If this were the case, it would be necessary to demonstrate that there is a cortical area, damage to which causes deficits on the POS-SO task but not in the SDR task. No such executive area has yet been discovered, and the requisite double dissociation remains to be demonstrated. At present, a parsimonious interpretation of our data is that the storage and processing components of working memory are inextricable within informational domains.

Our failure to demonstrate impairment in the POS-SO task after DM lesions (areas 9 and 8B) indicates that these regions are no more essential for self-ordering spatial information than they are for the simple maintenance of spatial information. These results are in accord with a study by Passingham (1985), in which monkeys were taught to retrieve rewards hidden behind 25 small doors without returning to the same location twice, thus engaging self-monitoring and serial organization of mental representations. Yet, lesions of the principal sulcus produced a marked impairment in this task, whereas dorsomedial frontal convexity lesions [similar to our DM lesions and to the mid-frontal lesion of Petrides (1995)] failed to do so.

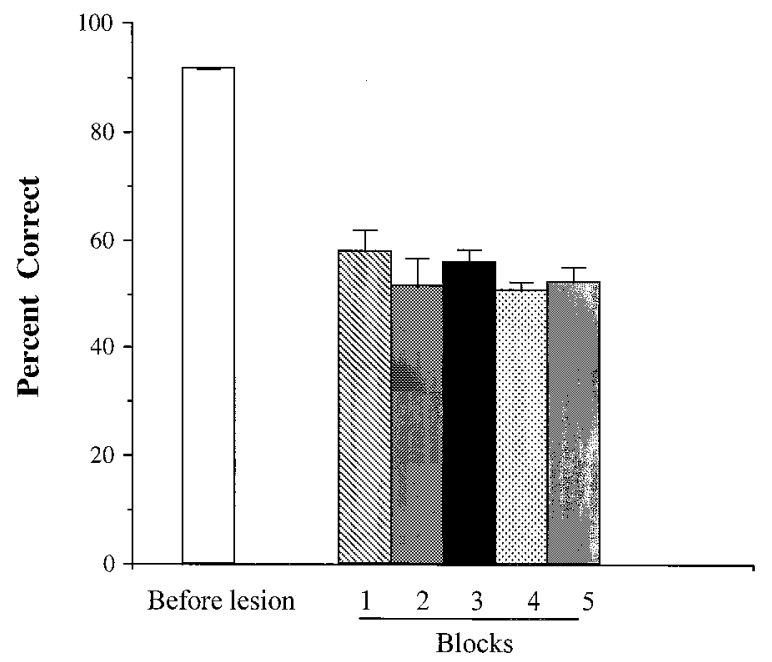

Figure 6. Mean percentage correct responses in the SDR tasks before and after DL lesions. Postoperative performance is represented in five bar graphs, each of which is the average of a block of five consecutive sessions. Monkeys received 25 sessions in the postoperative phase. As this Figure shows, there was little, if any, absence of improvement in performance throughout the 25 postoperative sessions in the DL lesion group.

Neither DL nor DM lesions produced impairments on the OBJ-SO task, suggesting that neither subregion is critical for accomplishing this task. This result differs from those obtained by Petrides (1995) in which monkeys with mid-frontal lesions were profoundly impaired on a nonspatial SO task similar to that used in the present study. However, the two studies differ in several ways. The resection in the Petrides study (1995) corresponds closely to our DM lesion because it removed mainly areas 9 and $8 \mathrm{~B}$ and largely spared the principal sulcus in most animals. However, even if a small part of area 46 were included in the lesion, this fact cannot explain the discrepancy between the two studies because there is no reason to suspect that a DM + DL lesion would produce a deficit that neither the DM nor DL lesions produce separately. We believe that methodological differences may be the more significant factor in explaining the discrepancies between the two studies. Thus, in Petrides' study, the monkeys' performance was evaluated in 40 trials (one trial per day over $40 \mathrm{~d}$ ), whereas in the present study, monkeys were tested for 250 trials (10 trials per day for $25 \mathrm{~d}$ ), unless they reached criterion earlier. When we performed an analysis on only the first 40 postoperative trials, the performance of the monkeys with DM lesions was $\sim 55-60 \%$ correct for both OBJ-SO and POS-SO tasks, similar to Petrides' result. However, monkeys in the present study received six times as many trials as did monkeys in the Petrides study, and as training progressed, performance progressively increased to criterion on the two self-ordering tasks. Thus, the deficit produced on these tasks by DM lesions is transient. We also observed a transient decrease in the level of performance on the same task after DL lesions. Monkeys with DL lesions performed at $\sim 57 \%$ correct on the first 40 trials and thereafter reached criterion. Altogether, these findings suggest that both DM and DL lesions induce a transient and nonspecific deficit in SO tasks, but only DL lesions produce a profound and lasting domain-specific deficit that is present throughout training.

Toward a model of functional segregation of WM within the lateral PFC in nonhuman primates

One model of functional organization of the lateral PFC proposes that it is a unitary association cortex that integrates information in 
A. POS-SO task

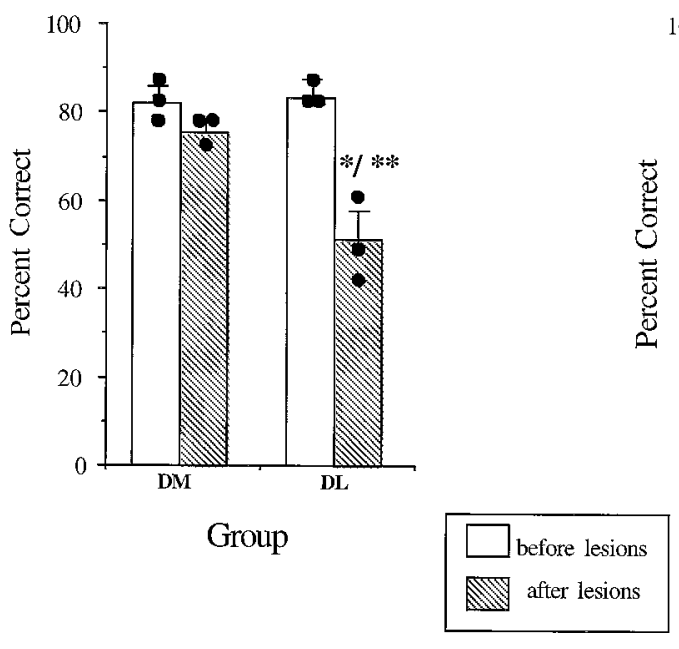

B. OBJ-SO task

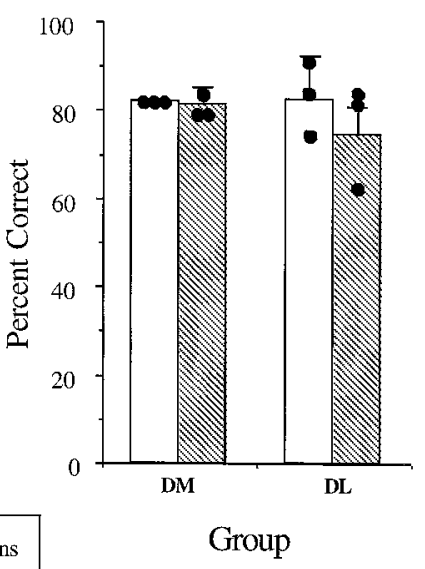

Figure 7. Mean percentage correct sequences in the POS-SO and OBJ-SO tasks for the two groups of monkeys before and after lesions. Each solid circle represents the score of one monkey. $D M$, Dorsomedial convexity group; $D L$, dorsolateral group. *Statistically significant $(p<0.05)$ withingroup comparison; ** statistically significant $(p<0.005)$ when compared with the group of monkeys with DM lesions.
WM, regardless of the level of processing within this domain. This specialization is supported by a wealth of single-unit recording studies of areas 46/8a neurons engaged in short-term spatialmnemonic functions (Fuster and Alexander, 1971; Kubota and Niki, 1971; Kojima and Goldman-Rakic, 1982; Funahashi et al., 1989, 1990, 1991; Carlson et al., 1990, 1997; Wilson et al., 1993), as well as numerous anatomical studies (Mesulam et al., 1977; Barbas and Mesulam, 1985; Selemon and Goldman-Rakic, 1988; Cavada and Goldman-Rakic, 1989). Although the present study does not specify a particular area for nonspatial WM processing, several studies indicate that the inferior convexity (mainly Walker's areas 12/45) is specialized for nonspatial processing (Passingham, 1975; Mishkin and Manning, 1978; Bachevalier and Mishkin, 1986; Wilson et al., 1993; O’Scalaidhe et al., 1997, 1999).

One may raise the question of the location of a "central executive" processor (Baddeley, 1996). Our data clearly demonstrate that increasing the load and the manipulation within WM did not recruit the DM region. However, these results do not rule out the involvement of another PFC area in the most complex aspects of executive functions. Alternatively, it is reasonable and appealing that each prefrontal module, networked with sensory, motor, limbic, and association areas (Selemon and GoldmanRakic, 1988), can support domain-specific executive operations. As mentioned above, the present study does not fully resolve this question because monkeys with DL lesions exhibited a profound impairment even at the level of basic WM processes. Nevertheless, a wide range of operations integral to working memory, including preparation, inhibition, or sequencing of motor responses and context contingencies have recently been observed in DL cortex (Funahashi et al., 1993, 1997; Wilson et al., 1994; Watanabe, 1996). Thus, the intrinsic neuronal circuitry within the DL area provides for a spectrum of functions compatible with all levels of WM operations, including executive operations. Finally, a single area devoted exclusively to supramodal executive functions has not yet been unequivocally identified in either the nonhuman primate brain or the human brain. At the same time, considerable evidence from neurophysiological and anatomical investigations in monkeys (see introductory remarks) and functional imaging studies of human cognition (Smith et al., 1995, 1996; Courtney et al., 1996, 1998; McCarthy et al., 1996; Belger et served in both simple and complex spatial WM tasks confirm and extend the evidence for a specialization of DL cortex for spatial 
al., 1998; Kelley et al., 1998; R. Adcock, T. Constable, J. Gore, and P. S. Goldman-Rakic, unpublished observations) is compatible with a parallel organization of domain-specific modules within the PFC.

\section{REFERENCES}

Bachevalier J, Mishkin M (1986) Visual recognition impairment follows ventromedial but not dorsolateral prefrontal lesions in monkeys. Behav Brain Res 20:249-261.

Baddeley A (1996) The fractionation of working memory. Proc Natl Acad Sci USA 93:13468-13472.

Barbas H, Mesulam M-M (1985) Cortical afferent input to the principalis region of the rhesus monkey. Neuroscience 15:619-637.

Bauer RH, Fuster JM (1976) Delayed-matching and delayed-response deficit from cooling dorsolateral prefrontal cortex in monkeys. J Comp Physiol Psychol 90:293-302.

Belger A, Puce A, Krystal JH, Gore JC, Goldman-Rakic P, McCarthy G (1998) Dissociation of mnemonic and perceptual processes during spatial and nonspatial working memory using fMRI. Hum Brain Mapp 6:14-32.

Butters N, Pandya DN (1969) Retention of delayed-alternation: effect of selective lesion of sulcus principalis. Science 165:1271-1273.

Butters N, Pandya D, Sanders K, Dye P (1971) Behavioral deficits in monkeys after selective lesions within the middle third of sulcus principalis. J Comp Physiol Psychol 72:132-144.

Butters N, Pandya D, Stein D, Rosen J (1972) A search for the spatial engram within the frontal lobes of monkeys. Acta Neurobiol Exp 32:305-329.

Carlson S, Tanila H, Pertovaara A, Lahteenmaki A (1990) Vertical and horizontal coding of space in the monkey dorsolateral prefrontal cortex. Brain Res 527:145-149.

Carlson S, Rama P, Tanila H, Linnankoski I, Mansikka H (1997) Dissociation of mnemonic coding and other functional neuronal processing in the monkey prefrontal cortex. J Neurophysiol 77:761-774.

Cavada C, Goldman-Rakic PS (1989) Posterior parietal cortex in rhesus monkey: II. Evidence for segregated corticocortical networks linking sensory and limbic areas with the frontal lobe. J Comp Neurol 287:422-445.

Courtney SM, Ungerleider LG, Keil K, Haxby JV (1996) Object and spatial working memory activate separate neural system in human cortex. Cereb Cortex 6:39-49.

Courtney SM, Petit L, Maisog JM, Ungerleider LG, Haxby JV (1998) An area specialized for spatial working memory in human frontal cortex. Science 279:1347-1351.

Funahashi S, Bruce CJ, Goldman-Rakic PS (1989) Mnemonic coding of visual space in the monkey's dorsolateral prefrontal cortex. J Neurophysiol 61:331-349.

Funahashi S, Bruce CJ, Goldman-Rakic PS (1990) Visuospatial coding in primate prefrontal neurons revealed by oculomotor paradigm. J Neurophysiol 63:811-831.

Funahashi S, Bruce CJ, Goldman-Rakic PS (1991) Neuronal activity related to saccadic eye movements in the monkey's dorsolateral prefrontal cortex. J Neurophysiol 65:1464-1483.

Funahashi S, Chafee MV, Goldman-Rakic PS (1993) Prefrontal neuronal activity in rhesus monkeys performing a delayed anti-saccade task. Nature 365:753-756.

Funahashi S, Inoue M, Kubota K (1997) Delay-period activity in the primate prefrontal cortex encoding multiple spatial positions and their order of presentation. Behav Brain Res 84:203-223.

Fuster J (1989) The prefrontal cortex. New York: Raven.

Fuster JM, Alexander GE (1971) Neuron activity related to short-term memory. Science 173:652-654

Fuster JM, Bauer RH (1974) Visual short-term memory deficit from hypothermia of frontal cortex. Brain Res 81:393-400.

Goldman PS (1971) Functional development of the prefrontal cortex in early life and the problem of neuronal plasticity. Exp Neurol 32:366-387.

Goldman-Rakic PS (1987) Circuitry of primate prefrontal cortex and regulation of behaviour by representational memory. In: Handbook of physiology, Vol 5 (Plum F, Mouncastle U, eds), pp 373-417. Washington, DC: The American Physiological Society.

Goldman-Rakic PS (1995) Architecture of the prefrontal cortex and the central executive. Ann NY Acad Sci 769:71-83.

Kelley WM, Miezin FM, McDermott KB, Buckner RL, Raichle ME,
Cohen NJ, Ollinger JM, Akbudak E, Conturo TE, Snyder AZ, Petersen SE (1998) Hemispheric specialization in human dorsal frontal cortex and medial temporal lobe for verbal and nonverbal memory encoding. Neuron 20:927-936.

Kojima S, Goldman-Rakic PS (1982) Delay-related activity of prefrontal neurons in rhesus monkeys performing delayed response. Brain Res 248:43-49.

Kowalska DM, Bachevalier J, Mishkin M (1991) The role of the inferior prefrontal convexity in performance of delayed nonmatching-tosample. Neuropsychologia 29:583-600.

Kubota K, Niki H (1971) Prefrontal cortical unit activity and delayed cortical unit activity and delayed alternation performance in monkeys. J Neurophysiol 34:337-347.

Levy R, Goldman-Rakic PS (1997) Segregation of working memory functions in prefrontal cortex in primates. Soc Neuroci Abstr 23:501.

McCarthy G, Puce A, Constable RT, Krystal JH, Gore JC, GoldmanRakic P (1996) Activation of human prefrontal cortex during spatial and nonspatial working memory tasks measured by functional MRI. Cereb Cortex 6:600-611.

Mesulam M-M, Van Hoesen GW, Pandya DN, Geschwind N (1977) Limbic and sensory connections of the inferior parietal lobule (area PG) in the rhesus monkey: a study with a new method for horseradish peroxidase histochemistry. Brain Res 136:393-414.

Meunier M, Bachevalier J, Mishkin M (1997) Effects of orbital frontal and anterior cingulate lesions on object and spatial memory in rhesus monkeys. Neuropsychologia 35:999-1015.

Mishkin M, Manning FJ (1978) Non-spatial memory after selective prefrontal lesions in monkeys. Brain Res 143:313-323.

Mishkin M, Murray EA (1994) Stimulus recognition. Curr Opin Neurobiol 4:200-206.

O'Scalaidhe SP, Wilson FA, Goldman-Rakic PS (1997) Areal segregation of face-processing neurons in prefrontal cortex. Science 278:1135-1138.

O'Scalaidhe SP, Wilson FA, Goldman-Rakic PS (1999) Face selective neurons in the prefrontal cortex of the macaque. Cereb Cortex, in press.

Owen AM (1997) The functional organization of working memory processes within human lateral frontal cortex: the contribution of functional neuroimaging. Eur J Neurosci 9:1329-1339.

Owen AM, Milner B, Petrides M, Evans AC (1996a) Memory for object features versus memory for object location: a positron-emission tomography study of encoding and retrieval processes. Proc Natl Acad Sci USA 93:9212-9217.

Owen AM, Evans AC, Petrides M (1996b) Evidence for a two-stage model of spatial working memory processing within the lateral frontal cortex: a positron emission tomography study. Cereb Cortex 6:31-38.

Owen AM, Stern CE, Look RB, Tracey I, Rosen BR, Petrides M (1998) Functional organization of spatial and nonspatial working memory processing within the human lateral frontal cortex. Proc Natl Acad Sci USA 95:7721-7726.

Passingham R (1975) Delayed matching after selective prefrontal cortex lesions in monkeys (Macaca mulatta). Brain Res 92:89-102.

Passingham RE (1985) Memory of monkeys (Macaca mulatta) with lesions in prefrontal cortex. Behav Neurosci 99:3-21.

Petrides M (1995) Impairments on nonspatial self-ordered and externally ordered working memory tasks after lesions of the mid-dorsal part of the lateral frontal cortex in the monkey. J Neurosci 15:359-375.

Petrides M, Milner B (1982) Deficits on subject-ordered tasks after frontal- and temporal-lobe lesions in man. Neuropsychologia 20:249-262.

Petrides M, Alivisatos B, Evans AC, Meyer E (1993) Dissociation of human mid-dorsolateral from posterior dorsolateral frontal cortex in memory processing. Proc Natl Acad Sci USA 90:873-877.

Quintana J, Fuster JM (1993) Spatial and temporal factors in the role of prefrontal and parietal cortex in visuomotor integration. Cereb Cortex 3:122-132.

Rainer G, Asaad WF, Miller EK (1998) Selective representation of relevant information by neurons in the primate prefrontal cortex. Nature 393:577-579.

Rao SC, Rainer G, Miller EK (1997) Integration of what and where in the primate prefrontal cortex. Science 276:821-824.

Selemon LD, Goldman-Rakic PS (1988) Common cortical and subcortical targets of the dorsolateral prefrontal and posterior parietal cortices in the rhesus monkey: evidence for a distributed neural network subserving spatially guided behavior. J Neurosci 8:4049-4068. 
Smith EE, Jonides J, Koeppe RA, Awh E, Schumacher E, Minoshima S (1995) Spatial vs object working memory: PET investigations. J Cognit Neurosci 7:337-358.

Smith EE, Jonides J, Koeppe RA (1996) Dissociating verbal and spatial working memory using PET. Cereb Cortex 6:11-20.

Stamm JS, Rosen SC (1973) The locus and crucial time of implication of prefrontal cortex in delayed response tasks. In: Psychophysiology of the frontal lobes (Pibram HK, Luria AR, eds), pp 139-153. New York: Academic.

Tanila H, Carlson S, Linnankoski I, Lindroos F, Kahila H (1992) Functional properties of dorsolateral prefrontal cortical neurons in awake monkey. Behav Brain Res 47:169-180.

Tanila H, Carlson S, Linnankoski I, Kahila H (1993) Regional distribu- tion of functions in dorsolateral prefrontal cortex of the the monkey. Behav Brain Res 53:63-71.

Ungerleider LG, Courtney SM, Haxby JV (1998) A neural system for human visual working memory. Proc Natl Acad Sci USA 95:883-890.

Watanabe M (1996) Reward expectancy in primate prefrontal neurons. Nature 382:629-632.

Wilson FA, O'Scalaidhe SP, Goldman-Rakic PS (1993) Dissociation of object and spatial processing domains in primate prefrontal cortex. Science 260:1955-1958.

Wilson FA, O'Scalaidhe SP, Goldman-Rakic PS (1994) Functional synergism between putative $\alpha$-aminobutyrate-containing neurons and pyramidal neurons in prefrontal cortex. Proc Natl Acad Sci USA 91:4009-4013. 